\title{
VEINTICINCO AÑOS DE PODER JUDICIAL
}

\author{
SUSANA GARCÍA COUSO \\ Profesora Titular de Derecho Constitucional \\ Universidad Rey Juan Carlos
}

\section{MARIEN AGUILERA MORALES}

Profesora Asociada de Derecho Procesal

Universidad Complutense de Madrid 


\section{SUMARIO}

INTRODUCCIÓN. I. LOS PRINCIPIOS INFORMADORES. 1. Origen popular de la Justicia. 2. Unidad jurisdiccional. 3. Exclusividad jurisdiccional. 4. Independencia de Jueces y Magistrados. II. Principios ORganizativos. 1. EI Gobierno del Poder Judicial. 2. El estatuto jurídico de Jueces y Magistrados. 3. El diseño organizativo de la jurisdicción ordinaria. 4. El Ministerio Fiscal. 5. La policía judicial. III. PRINCIPIOS PROCESALES. IV. LA PARTICIPACIÓN DE LA JURISDICCIÓN ORDINARIA EN LA DEFENSA DE LA CONSTITUCIÓN. 


\title{
VEINTICINCO AÑOS DE PODER JUDICIAL
}

POR

\author{
SUSANA GARCÍA COUSO \\ Profesora Titular de Derecho Constitucional \\ Universidad Rey Juan Carlos \\ MARIEN AGUILERA MORALES \\ Profesora Asociada de Derecho Procesal \\ Universidad Complutense de Madrid
}

\section{INTRODUCCIÓN}

El Poder Judicial se ha convertido en un elemento clave de nuestro sistema democrático en tanto éste, superados aquellos planteamientos históricos que basaban su configuración en la subordinación a los demás Poderes del Estado incluso negándole la consideración de auténtico Poder, se reconoce como tal con posibilidades no sólo de interpretación normativa, sino de control del resto de los Poderes; una fiscalización del Ejecutivo que lleva a cabo a través del control judicial de la Administración, e incluso del Poder Legislativo a través de su participación en el control de la constitucionalidad de las leyes.

Un Poder crucial en estos veinticinco años de funcionamiento de Estado democrático y de aplicación de la Constitución, que se ha visto desarrollado por distintas normas, especialmente por la Ley Orgánica del Poder Judicial - que derogó definitivamente la Ley de 1870-. $y$ que se ha intentado potenciar $y$ agilizar en su funcionamiento a través de la elaboración del Libro Blanco del Poder Judicial y del Minis- 
terio Fiscal, así como con el «Pacto de Estado para la reforma de la Justician, firmado el 28 de mayo de 2001 entre el PP y el PSOE, y que ha dado sus frutos con reformas como la operada por la Ley Orgánica 2/2001, de 28 de junio, sobre composición del Consejo General del Poder Judicial; la de la Ley de Enjuiciamiento Criminal, realizada en virtud de la Ley 38/2002, de 24 de octubre y de la Ley Orgánica 8/2002, de idéntica fecha; o la del Código Penal, realizada en virtud de la Ley Orgánica 11/2003, de 29 de septiembre; así como con nuevos textos legales como el Real Decreto 688/2001, de 22 de junio, y el Real Decreto $1281 / 2002$, de 5 de diciembre, por los que se aprueban, respectivamente, el Estatuto de Abogados y Procuradores, y, más recientemente, con la Ley 22/2003, de 9 de julio, Concursal, y la Ley Orgánica de medidas concretas en materia de seguridad ciudadana, violencia doméstica e integración social de los extranjeros. En aquel Pacto se prevén, además, otras muchas medidas. Así: la potenciación delTribunal Supremo como órgano jurisdiccional superior y garante de la unidad de doctrina en todos los órdenes jurisdiccionales, reformando el recurso de casación y de revisión; la reforma de la Ley Orgánica del Tribunal Constitucional, para potenciar y agilizar su función como intérprete supremo de la Constitución y como garante de los derechos y libertades fundamentales que en ella se consagran; la redefinición de competencias de los Tribunales Superiores de Justicia, adaptándose al Estado de las Autonomías; la aprobación de un nuevo mapa judicial que permita agilizar y acercar la justicia al ciudadano; la reforma de la carrera judicial y la elaboración de un nuevo estatuto de Jueces y Magistrados; la redefinición de las funciones de los Secretarios Judiciales; un nuevo diseño de la Oficina Judicial; la elaboración de Planes sobre nuevas tecnologías, infraestructuras y financiación; o la adaptación del marco competencial de las Comunidades Autónomas. Algunas de estas medidas se hallan, actualmente, en fase de tramitación parlamentaria; así, por ejemplo, cabe citar el Proyecto de Ley Orgánica de Reforma de la Ley de Enjuiciamiento Criminal en materia de prisión provisional; el Proyecto de Ley Orgánica por el que se modifica el Código Penal, y el Proyecto de Ley Orgánica de Reforma de la Ley Orgánica del Poder Judicial.

El diseño constitucional del Poder Judicial se basa en principios contenidos en el Título VI de la Constitución, entre los que cabe distinguir aquellos denominados por la doctrina «informadores" del Poder Judicial, de carácter general y configurador; los principios de carácter estrictamente procesal; y los principios organizativos, así como el status jurídico de sus miembros. 


\section{LOS PRINCIPIOS INFORMADORES DEL PODER JUDICIAL}

El artículo 117. 1 de la Constitución establece que "la Justicia emana del Pueblo y se administra en nombre del Rey por Jueces y Magistrados integrantes del Poder Judicial». De esta afirmación parte uno de los principios fundamentales que se desprenden del Título VI de la Constitución y que pueden llegar a determinar la posición constitucional del Poder Judicial: el origen popular de la Justicia. A este principio se unen otros como el de la independencia tanto externa como interna de Jueces y Magistrados (art. 117.1); la exclusividad jurisdiccional, ésta última reconocida en el artículo 117. 3 cuando establece que «el ejercicio de la potestad jurisdiccional ejecutando y haciendo ejecutar lo juzgado corresponde exclusivamente a Jueces y Tribunales determinados por las leyes, según las normas de competencia y procedimiento" y en su apartado 4, cuando señala que "los Jueces y Magistrados no ejercerán más funciones que las ya señaladas $y$ las que le sean atribuidas por ley en garantía a cualquier derecho"; y, por último, la unidad jurisdiccional que define el Poder Judicial como único del Estado (art. 117.5).

Los principios arriba mencionados han sido desarrollados a lo largo de estos veinticinco años de vigencia de la Constitución española fundamentalmente por la Ley Orgánica 6/1985, de 1 de julio, del Poder Judicial, sometida a varias reformas parciales, entre otras, la operada en virtud de la Ley Orgánica 16/1994, de 8 de noviembre, declarada plenamente constitucional por la STC 105/2000, de 13 de abril; la Ley Orgánica 5/1997, de 4 de diciembre; la Ley Orgánica 6/1998, de 13 de julio; la Ley Orgánica 13/1999, de 14 de mayo; la Ley-Orgánica 9/2000, de 22 de diciembre, sobre medidas urgentes para la agilización de la Administración de Justicia; la Ley Orgánica 2/2001, de 28 de junio: la Ley Orgánica 6/2002, de 27 de junio, de Partidos Políticos; y, por último, la Ley Orgánica 8/2003, de 9 de julio, de Reforma Concursal.

\section{Origen popular de la Justicia}

Una vez destacada la legitimación democrática que se desprende del artículo 117.1 de la Constitución sobre el Poder Judicial, es necesario apuntar que de este principio se derivan otras manifestaciones importantes como son la posibilidad de ejercer la acción popular por parte de los ciudadanos y de participar en la Administración de Justicia mediante la institución del Jurado, así como de los Tribunales consuetudinarios y tradicionales. Estas otras manifestaciones -que go- 
zan de reconocimiento en el artículo 125 de la Constitución- dejan entrever algunas de las formas con que, durante estos años, se ha concretado la participación ciudadana en la Administración de Justicia. En función del grado de intensidad en que se ha traducido esa participación, esas formas pueden reconducirse a estas tres: en primer lugar, el ejercicio mismo de funciones jurisdiccionales por parte de los ciudadanos; en segundo lugar, el amplio margen de accesibilidad de aquéllos a la Justicia; y, en tercer lugar, el reconocimiento y garantía de sus derechos ante la Administración de Justicia.

\section{a) Ejercicio de funciones jurisdiccionales}

La participación ciudadana en la Administración de Justicia encuentra su máxima expresión en la atribución de funciones jurisdiccionales a determinados órganos integrados por personas que no son profesionales del Derecho ni pertenecen a la Carrera Judicial, tal es el caso del Tribunal del Jurado, de los Tribunales consuetudinarios y tradicionales $y$ de los Jueces de Paz.

El Tribunal del Jurado fue reintroducido en nuestro ordenamiento jurídico en virtud de la Ley Orgánica 5/1995, de 22 de mayo. Esta Ley consagró el derecho constitucional de participación directa de los ciudadanos en los asuntos públicos, articulando tal derecho en relación con la Administración de Justicia como un derechodeber y optando por un modelo de Jurado puro, de corte anglosajón. Esto último, unido al tipo de delitos que se someten a la deliberación y veredicto del Tribunal popular, a la creación de un procedimiento especial para tal clase de causas, y a las funciones que se confían a los miembros legos de aquel Tribunal (repárese que entre las funciones del Jurado no sólo está la de declarar probada la participación del imputado en el hecho delictivo, sino también la de fijar los elementos normativos del hecho en cuestión, motivando el porqué de su decisión) ha provocado, en opinión de algunos, la necesidad de reformar la institución. De esta necesidad se ha hecho eco el tantas veces citado "Pacto de Estado para la Reforma de la Justician, entre cuyos objetivos se incluye la readaptación del sistema de jurado a la luz de la experiencia observada en su funcionamiento, y que, en el momento de escribir estas páginas, aún no se ha hecho realidad.

Como apuntábamos, el legislador también ha amparado la participación ciudadana en la Administración de Justicia a través de los 
Tribunales consuetudinarios y tradicionales. Concretamente, el artículo 19 de la Ley Orgánica del Poder Judicial confiere tal carácter al Tribunal de las Aguas de la Vega Valenciana y al denominado Consejo de Hombres Buenos de Murcia.

Aunque, a diferencia de los anteriores, no existía imperativo constitucional al respecto, la Ley Orgánica del Poder Judicial (arts. 99 a 103) tuvo a bien abrir un tercer cauce de participación ciudadana en el Poder Judicial a través de los Juzgados de Paz. Legos en Derecho y nombrados a propuesta de los Ayuntamientos, los Jueces de Paz ejercen la función jurisdiccional con el mismo status jurídico que los Jueces y Magistrados de Carrera. Su ámbito competencial - con los años más reducido y simbólico - ha llevado a replantearse si en el futuro es o no aconsejable su mantenimiento.

\section{b) Acceso a la Justicia}

Una segunda forma de participación popular en la Administración de Justicia se encauza por la vía de atribuir al justiciable el derecho de pretender una tutela judicial. En este caso, por tanto, aquella participación no se traduce en el ejercicio de la función jurisdiccional sino en instar ese ejercicio de los Tribunales.

La anterior posibilidad - erigida en derecho fundamental por la propia Constitución, en la medida en que el derecho de acceso a la jurisdicción constituye el contenido primordial y básico del derecho a la tutela judicial efectiva (art. 24.1) - se ha traducido, en el plano legislativo, en permitir que cualquier derecho subjetivo o interés legítimo pueda tener acceso a la tutela de nuestros Tribunales; $y$, en el plano jurisprudencial, en una interpretación de los presupuestos y requisitos procesales conforme al denominado principio pro actione o, lo que es lo mismo, en una interpretación lo más favorable posible a la tutela jurisdiccional. En este último sentido, es de destacar la copiosa jurisprudencia constitucional que, durante estos años, ha garantizado a los justiciables el derecho de obtener de los órganos jurisdiccionales una resolución sobre el fondo del asunto y, antes aún, de poder acceder a los Tribunales de Justicia solicitando la tutela de cualquier derecho o interés legítimo.

Peculiar manifestación del derecho de acceder a la Justicia en el ámbito del proceso penal es el derecho, que el artículo 125 de la Constitución reconoce a todos los ciudadanos, de ejercer la acción popular. Dos son las razones que hacen de este derecho algo peculiar: la 
primera es que, a diferencia de otros ordenamientos jurídicos, el nuestro reconoce legitimación activa para su ejercicio no sólo al Ministerio Fiscal, sino también a cualquier ciudadano, haya sido o no ofendido por el delito; la segunda, es que, a diferencia de lo que sucede con el derecho a la tutela judicial efectiva, el ejercicio de la acción popular no es derecho que se reconozca toda persona, sino -lo que es bien distinto - a todo ciudadano.

El derecho constitucional al ejercicio de la acción popular, que fue recogido hace ya más de un siglo por la Ley de Enjuiciamiento Criminal (arts. 101 y 270), no ha sido objeto de desarrollo legislativo posterior, aunque si de aclaraciones y precisiones tanto por parte del legislador como de la jurisprudencia. Así, el artículo 19.1 de la Ley Orgánica del Poder Judicial circunscribe la acción popular a los ciudadanos de nacionalidad española, lo que es tanto como decir que los extranjeros pueden ejercitar la acción penal pero sólo en la medida en que ellos o sus representados sean perjudicados $u$ ofendidos por el hecho delictivo, o como afirmar que la acusación popular es posición únicamente reservada a los ciudadanos españoles. Por su lado, la jurisprudencia, además de esclarecer la diferencia entre acusación popular y particular (diferencia legalmente no apreciada), ha adoptado una interpretación amplia o no restrictiva del término "ciudadano" hasta el punto de reconocer legitimación a las personas jurídicas para mostrarse parte en un proceso penal como acusadores populares.

\section{c) Reconocimiento y garantía de determinados derechos del ciudadano ante la Administración de Justicia}

La aproximación y apertura de la Justicia a los ciudadanos también se ha dejado sentir en el reconocimiento de los derechos de éstos para con aquélla y en la posibilidad de exigir el cumplimiento de tales derechos o de garantizar su efectividad. Ambos objetivos, junto al de ofrecer una Justicia más abierta, transparente y ágil para los ciudadanos - sobre todo para quienes se encuentran más desprotegidosconstituyen la razón de ser de la ya mencionada Carta de Derechos de los ciudadanos ante la Justicia, aunque también la de buena parte de las reformas que en los últimos años se han realizado de nuestro ordenamiento jurídico. 


\section{Unidad jurisdiccional}

El principio de unidad jurisdiccional supone que el Poder Judicial es único para todo el territorio español, siendo la Administración de Justicia una competencia exclusiva del Estado (art. 149.1.5. ${ }^{a} \mathrm{CE}$ ). No obstante, y como es sabido, cabe la asunción de competencias por parte de las Comunidades Autónomas en lo que se ha venido a denominar jurisprudencialmente la «administración de la Administración de Justicia»; expresión comprensiva de aquellas competencias que, sin ser función jurisdiccional propiamente dicha (función ejercida de forma exclusiva por jueces y magistrados y cuyo gobierno corresponde al CGPJ), coadyuvan al ejercicio de la misma. Sobre el tema de las competencias de las Comunidades Autónomas en materia de "administración de la Administración de Justicia» tuvo ocasión de pronunciarse el Tribunal Constitucional en sentencias como la 56/1990, de 29 de marzo; 62/1990, de 30 de marzo; y 158/1992, de 26 de octubre. Por tanto, mientras la potestad jurisdiccional es competencia exclusiva del Estado, y, por ello, cuestión sustraída al ámbito competencial de las Comunidades Autónomas, lo relativo a la dotación de medios materiales y del personal al servicio de la Administración de Justicia es materia sobre la que pueden tener competencia el Estado, el Consejo General del Poder Judicial y las Comunidades Autónomas.

La existencia de títulos competenciales en favor de las Comunidades Autónomas ha hecho que durante estos años se les hayan ido transfiriendo competencias en toda una serie de materias referentes a la Administración de Justicia. En concreto, competencias ejecutivas y de gestión sobre el personal no judicial al servicio de la Administración de Justicia, y competencias sobre medios materiales y sobre determinadas facultades de colaboración para la mejora de la función jurisdiccional. Además, conviene tener en cuenta que, ya desde un inicio, algunos Estatutos de Autonomía optaron por incluir en ellos la figura del Tribunal Superior de Justicia, entendida como instancia suprema en el territorio de la Comunidad Autónoma, siendo la LOPJ de 1985 la que generalizara la inclusión de este órgano jurisdiccional y la que, a su vez, delimitara la participación de las Comunidades en la organización de la demarcación judicial de su territorio.

Pensemos también en otras cuestiones como la regulación del uso de las lenguas cooficiales en los procesos o en la evaluación de su conocimiento para el acceso a determinadas categorías judiciales previstas en algunos Estatutos y en la propia Ley Orgánica del Poder Judicial, o en otras, todavía pendientes de efectiva adopción, como la 
atribución del conocimiento de recursos extraordinarios a los Tribunales Superiores de Justicia.

En este orden de ideas, requiere especial mención la reforma de los Estatutos de Autonomía efectuada en 1994, que produjo una cierta homogeneización entre las diversas Comunidades Autónomas, y la reforma de la Ley Orgánica del Poder Judicial de 1994, que supuso la posibilidad de transferencia a las Comunidades Autónomas de competencias en toda una serie de materias como medios materiales y personales; Administración penitenciaria; protección y tutela de menores; informatización de órganos judiciales; normalización lingüística; y policía judicial. En la actualidad se han asumido traspasos por las Comunidades Autónomas del País Vasco, Cataluña, Galicia, Andalucia, Comunidad Valenciana, Canarias y Madrid.

Todo esto ha producido ciertos solapamientos entre el Ministerio de Justicia, el CGPJ y las Comunidades Autónomas. En este sentido, el Libro Blanco de la Justicia, elaborado por el Consejo General del Poder Judicial en 1996, proponía una serie de medidas tendentes a evitar esa confluencia, pronunciándose decididamente a favor de la asunción por parte de las Comunidades Autónomas y el Consejo en detrimento del Ministerio de Justicia.

No obstante, y aun habiéndose realizado en la práctica una progresiva asunción de competencias por parte de las Comunidades Autónomas, se han seguido planteando por éstas debates en torno a cuestiones como la posibilidad de crear Consejos Generales del Poder Judicial en el ámbito autonómico e incluso, desde algunas posiciones nacionalistas, de crear un poder judicial propio.

Además de la denominada "vertiente territorial» del principio de unidad jurisdiccional a la que nos acabamos de referir, este principio presenta una segunda vertiente o faceta. Se trata de la vertiente «interna» del principio de unidad, esto es aquélla que proscribe la existencia de jurisdicciones especiales o, lo que es lo mismo, de determinados órganos jurisdiccionales integrados por jueces que no formen parte de la jurisdicción ordinaria. La razón de ser de esta prohibición puede encontrarse en el deseo de superar los errores de nuestro pasado histórico, en que abundaron las jurisdicciones especiales como el Tribunal de Orden Público, del que se dice que es el antecedente directo de la Audiencia Nacional.

Lo anterior no obstante, la propia Constitución ampara la existencia de Tribunales que, stricto sensu, no forman parte de la jurisdicción ordinaria. Es el caso del Tribunal Constitucional, del Tribunal de 
Cuentas o de los ya mencionados Tribunales tradicionales. También es el caso de la jurisdicción militar, cuya existencia quiso mantener el constituyente, aunque reducida al ámbito estrictamente castrense y a los supuestos de estado de sitio (art. 117.5). El reducido ámbito de actuación con que constitucionalmente se diseñó la jurisdicción militar se ha traducido en el plano legislativo en una profunda reforma de su estructura y de su normativa reguladora, a fin de acomodar la jurisdicción militar a los principios del Estado de Derecho. Esa reforma se ha acometido fundamentalmente en virtud de la Ley Orgánica 4/1987, de competencia y organización de la jurisdicción militar (recientemente modificada por Ley Orgánica 9/2003, de 15 de julio); de la Ley Orgánica 9/1988, de planta y organización territorial de la jurisdicción militar; de la Ley Orgánica 2/1989, Procesal Militar.

\section{Exclusividad jurisdiccional}

El constituyente diseñó la función jurisdiccional como función exclusiva de Jueces y Magistrados, lo que, de una parte, sustraía la posibilidad de que el legislador atribuyera potestad jurisdiccional a persona o entidad distinta de aquéllos $y$, de otra parte, imponía la necesidad de que Jueces y Magistrados no ejercieran más función que la jurisdiccional y las que expresamente les fueran atribuidas por ley en garantía de cualquier derecho (art. 117.4). Con base en esta última habilitación, la Ley Orgánica del Poder Judicial confió a Jueces y Magistrados funciones como la del Registro Civil (expresamente mencionada en la Constitución y que previamente a ella ya contemplaba la Ley del Registro Civil de 1957). Junto a ella, nuestros Jueces y Tribunales también realizan funciones no jurisdiccionales como la denominada jurisdicción voluntaria, regulada fundamentalmente en el Libro III de la Ley de Enjuiciamiento Civil de 1881, la autorización de determinados actos de los poderes públicos que lesionan o limitan derechos fundamentales, o su presencia en los órganos que componen la llamada Administración electoral.

\section{Independencia de Jueces y Magistrados}

La Ley Orgánica del Poder Judicial convierte la independencia de Jueces y Magistrados en uno de sus ejes centrales. Artículos como el 12 , en el que se reconoce frente a todos los órganos judiciales y de Gobierno del Poder Judicial, no pudiendo, a tal efecto, corregir la apli- 
cación o interpretación del ordenamiento jurídico hecha por sus inferiores sino en virtud de los recursos establecidos, ni dictar instrucciones de carácter general o particular sobre dicha interpretación o aplicación, es buena muestra de ello.

Precisamente los posibles ataques a la independencia judicial pueden provenir de dos frentes: en primer lugar, de los propios integrantes del Poder Judicial o de sus órganos de gobierno (independencia interna), y, en segundo lugar, desde otros poderes del Estado, incluido el denominado cuarto poder (independencia externa.) Así, por ejemplo, estos años han estado plagados de casos que, ante la opinión pública, se han tachado de ataques directos a la independencia del Poder Judicial. Sin ir más lejos, y por poner un ejemplo, los medios de comunicación atribuyeron la creación de los Juzgados Centrales de Vigilancia Penitenciaria a la intención de poner coto a determinadas decisiones judiciales que no se compadecían con la política antiterrorista del Gobierno. Son de destacar también los juicios paralelos realizados, desde la prensa y la opinión pública, sobre casos relevantes de la vida política y social española.

A la consagración legal de la independencia judicial se ha unido el establecimiento de determinadas garantías con las que se ha pretendido dotar de efectividad a aquel principio. Entre esas garantías puede citarse, a título de ejemplo, la propia existencia del Consejo General del Poder Judicial, creado para desapoderar al Ejecutivo de todo lo relativo al estatuto jurídico de Jueces y Magistrados; la exigencia misma de que lo referente a Jueces y Magistrados esté regulado por Ley Orgánica (exigencia en cierta medida desvirtuada por la atribución de potestad reglamentaria al Consejo General del Poder Judicial para regular cuestiones accesorias relativas al estatuto de Jueces y Magistrados); y el aseguramiento de una retribución económica digna a los integrantes de la carrera judicial, lo que se ha llevado a cabo en virtud de la Ley 15/2003, de 26 de mayo, reguladora del régimen retributivo de las carreras judicial y fiscal.

\section{PRINCIPIOS ORGANIZATIVOS}

\section{El gobierno del Poder Judicial}

El gobierno del Poder Judicial ha sido encomendado, como señala el artículo 122.2 de la Constitución, al Consejo General del Poder Judicial. 
Su creación por el constituyente de 1978 supuso toda una novedad pues, hasta ese momento, no habia existido en la historia del constitucionalismo español una figura similar, habiendo recaído esta competencia de forma exclusiva en el Ministerio de Justicia.

La concreción legislativa de este órgano no jurisdiccional tuvo lugar a través de la Ley Orgánica $1 / 1980$, de 10 de enero, posteriormente derogada por la Ley Orgánica 6/1985, del Poder Judicial.

La actuación del Consejo durante estos años de funcionamiento no ha dejado de causar polémica principalmente por el difícil asentamiento político $y$, sobre todo, social que ha sufrido como consecuencia del desapoderamiento competencial que ha supuesto en relación con el Gobierno, así como por su composición eminentemente política. Pensemos al respecto en las crisis producidas en 1993 y 1995, con la existencia de un elevado número de vacantes, y que acabarían en la crisis de marzo de 1996, en la que, tras una serie de dimisiones, se produjo una paralización del Pleno del Consejo por falta de quórum.

Precisamente esta última (esto es, la forma de elección de los miembros del Consejo) ha sido quizás la cuestión más polémica en la redacción de la Ley Orgánica del Poder Judicial, enfrentando a las diferentes fuerzas políticas. De hecho, han existido tres regulaciones distintas como consecuencia de las diferentes lecturas que del artículo 122. 3 se han realizado (recuérdese que, según este precepto, los veinte miembros del Consejo General del Poder Judicial serán elegidos, doce entre Jueces y Magistrados de todas las categorias judiciales, en los términos que establezca una Ley Orgánica, y los ocho restantes a propuesta del Parlamento, cuatro por el Congreso y cuatro por el Senado). Estas regulaciones se han diferenciado entre sí en función del modo de elegir los 12 vocales de origen judicial, haciendo recaer esta elección bien sobre los propios Jueces y Magistrados en activo, mediante sufragio universal, libre y secreto (sistema que con el que se eligieron de 1980 a 1985, tal y como preveía la Ley Orgánica del Consejo General del Poder Judicial de 1980); bien sobre el Congreso y el Senado, con lo que, al fin y al cabo, eran las Cortes las que procedían a la elección de los 20 vocales del Consejo (sobre este segundo sistema, introducido por la Ley Orgánica del Poder Judicial se pronunció el Tribunal Constitucional en sus Sentencias 45/1986, de 17 de abril, y, especialmente, en la 108/1986, de 29 de julio, por la que se desestimó el recurso planteado por el Grupo Parlamentario Popular contra la citada composición); bien sobre los Jueces y Magistrados, pero con participación de las Cámaras Parlamentarias. Este último sistema, «a caballo" entre los dos anteriores, fue introducido por la Ley Orgánica 
$2 / 2001$, de 28 de junio, sobre composición del Consejo. Sucintamente expuesto, el sistema de designación de los vocales de origen judicial que acuña esta Ley residencia en el Congreso y en el Senado la elección, respectivamente, de seis Vocales de entre una lista de treinta y seis candidatos presentados por las asociaciones profesionales de Jueces y Magistrados o por un número de éstos que represente al menos el 2 por 100 de todos los que se encuentran en servicio activo, según los criterios señalados en el artículo 112 LOPJ. Con esta última fórmula de elección se llevó a cabo el proceso del renovación del Consejo en el año 2001. No obstante, tampoco esta fórmula ha estado exenta de polémica.

A la supremacía del Consejo como órgano de gobierno de Jueces y Magistrados hay que unir la existencia de otros órganos de gobierno interno de Jueces y Magistrados como las Salas de Gobierno de determinadas Audiencias y Tribunales, los Jueces Decanos y las Juntas de Jueces.

\section{El estatuto jurídico de Jueces y Magistrados}

Los Jueces y Magistrados, como integrantes de un cuerpo único de funcionarios, tal y como establece el artículo 122 de la Constitución, cuentan con estatuto jurídico específico que fue desarrollado por la LOPJ. Este estatuto se caracteriza principalmente por la garantía de la independencia e imparcialidad a través del reconocimiento de la inamovilidad (arts. 378 y ss. LOPJ), la inmunidad penal (arts. 398 y ss. LOPJ), sus prerrogativas profesionales (arts. 383 a 385 LOPJ), las responsabilidades (arts. 405 a 427 LOPJ), el régimen de incompatibilidades (arts.389 y ss. LOPJ), o su régimen de enjuiciamiento (art. 405 LOPJ).

\section{El diseño organizativo de la jurisdicción ordinaria}

Aunque, según ya ha quedado dicho, el principio de unidad jurisdiccional constituye la base de la organización y funcionamiento de los Tribunales, el "hecho autonómico», de un lado, y la diversidad de asuntos que son sometidos al conocimiento de la jurisdicción ordinaria, de otro lado, han determinado una peculiar estructura de nuestros tribunales tanto desde el punto de vista de su organización y funcionamiento, como desde el punto de vista de su planta y demarcación. 
Por lo que hace a lo primero, esto es, a la organización y funcionamiento de los Juzgados y Tribunales que integran la jurisdicción ordinaria, la Ley Orgánica del Poder Judicial de 1985 estructuró ésta en cuatro órdenes o especialidades en función del tipo de materias sometidas a su conocimiento. Así las cosas, hoy día, los órganos jurisdiccionales que conforman aquella jurisdicción se integran en el orden civil, penal, contencioso-administrativo y laboral o social. Con todo, la especialización no se ha llevado hasta sus últimas consecuencias, pues hay determinados órganos como los Juzgados de Paz, los Juzgados de Primera Instancia e Instrucción, las Audiencias Provinciales o la Sala especial del Tribunal Supremo, prevista en el art. 61 LOPJ, que extienden su competencia sobre varias de aquellas materias.

Durante estos veinticinco años, los órdenes citados han sufrido alteraciones tanto en lo que hace a los concretos Juzgados y Tribunales que los han integrado, como a las materias atribuidas a cada uno de esos órganos jurisdiccionales. En ambas facetas, las alteraciones han consistido en supresiones y en añadidos. Así, mientras algunos órganos jurisdiccionales han desaparecido del inicial diseño organizativo de la jurisdicción ordinaria (v.gr.: Juzgados de Distrito; las Magistraturas de Trabajo y los Tribunales Tutelares de Menores), se han creado otros que no se contemplaban originariamente en la Ley Orgánica del Poder Judicial (v.gr.: Juzgados de lo Penal y Centrales de lo Penal; Juzgados de Menores y Centrales de Menores; Juzgados Centrales de Vigilancia Penitenciaria y Juzgados de lo Mercantil) o que, aun contemplándose, no fueron creados sino hasta muchos años después como los Juzgados de lo Contencioso-administrativo.

Dejando a un margen lo que fue y ya no es, el actual diseño organizativo de la jurisdicción ordinaria es, sucintamente expuesto, el que sigue:

Al orden civil pertenecen los siguientes órganos jurisdiccionales: los Juzgados de Paz, los Juzgados de Primera Instancia e Instrucción (o, simplemente, los Juzgados de Primera Instancia); las Audiencias Provinciales; la Sala de lo Civil y Penal de los Tribunales Superiores de Justicia (en cuanto Sala de lo Civil); y la Sala Civil (Sala Primera) del Tribunal Supremo. A esta lista deben unirse los, recientemente creados, Juzgados de lo Mercantil (L.O. 8/2003, de 9 de julio, para la Reforma Concursal). A estos Juzgados se les atribuye el conocimiento de cuantas cuestiones se susciten en materia concursal, así como aquellas otras cuestiones que se enumeran en el art. 86 ter LOPJ. 
Mucho más complejo es el diseño organizativo del orden penal de la jurisdicción. A este orden pertenecen: los Juzgados de Paz, Los Juzgados de Primera Instancia e Instrucción (o, simplemente, los Juzgados de Instrucción); los Juzgados de lo Penal; los Juzgados de Menores; los Juzgados de Vigilancia Penitenciaria; elTribunal del Jurado; las Audiencias Provinciales; la Sala de lo Civil y Penal de los Tribunales Superiores de Justicia; los Juzgados Centrales de Instrucción; los Juzgados Centrales de lo Penal; la Audiencia Nacional (Sala de lo Penal); los Juzgados Centrales de Menores; los Juzgados Centrales de Vigilancia Penitenciaria; y la Sala de lo Penal (Sala Segunda) del Tribunal Supremo. La pluralidad de órganos que integran este orden de la jurisdicción responde fundamentalmente a dos tipos de causas: la prime$\mathrm{ra}$, tiene que ver con la estructura de nuestro proceso penal (con dos fases bien diferenciadas: la fase de instrucción y la fase de juicio oral) y con el derecho a un juez imparcial o derecho al juez no prevenido, que impone la atribución de cada una de aquellas fases procesales a órganos distintos al objeto de soslayar que el Juez que dicte sentencia actúe con prejuicios adquiridos de la actividad investigadora previa; la segunda, con la existencia de ciertos órganos de carácter especial, esto es, de órganos que tienen atribuida la instrucción y/o el enjuiciamiento de determinadas causas penales, al margen de las reglas generales de atribución de la competencia; este último es el caso, por ejemplo, de la Audiencia Nacional (y de los Juzgados Centrales de Instrucción y de los Juzgados Centrales de lo Penal, en tanto actúan en el ámbito de las competencias de la Audiencia Nacional) $y$ del Tribunal del Jurado.

El orden contencioso-administrativo está integrado, por su parte, por los Juzgados de lo Contencioso-Administrativo, las Salas de lo Contencioso-Administrativo de los Tribunales Superiores de Justicia, los Juzgados Centrales de lo Contencioso-Administrativo, la Sala de lo Contencioso-Administrativo de la Audiencia Nacional y la Sala de lo Contencioso-Administrativo (SalaTercera) delTribunal Supremo. Como apuntábamos líneas arriba, aunque la LOPJ contemplaba los Juzgados de lo Contencioso-Administrativo entre los órganos de la jurisdicción ordinaria, aquéllos no entraron en funcionamiento hasta trece años después. Concretamente, su creación obedeció a la Ley de Jurisdicción Contencioso-Administrativa de julio de 1998, que también introdujo los Juzgados Centrales de lo Contencioso-Administrativo con el objeto de aliviar la excesiva carga competencial de la correspondiente Sala de la Audiencia Nacional.

Finalmente, integran el orden laboral o social de la jurisdicción los Juzgados de lo Social, que sustituyen a las antiguas Magistraturas 
de Trabajo, las Salas de lo Social de los Tribunales Superiores de Justicia, la Sala de lo Social de la Audiencia Nacional y la Sala de lo Social (Sala Cuarta) del Tribunal Supremo.

El ámbito competencial de cada uno de los Juzgados y Tribunales arriba citados, así como su ámbito de demarcación territorial, viene delimitado por la LOPJ. No obstante, respecto de la dotación y distribución en el territorio de aquellos órganos jurisdiccionales, las previsiones de la LOPJ han sido objeto de desarrollo en virtud de la Ley $38 / 1988$, de 28 de diciembre, de demarcación y planta judicial.

\section{El Ministerio Fiscal}

Pese al tratamiento detallado que la Constitución de 1978 dispensó al Ministerio Fiscal, el papel que está llamado a desempeñar en el ámbito de la Administración de Justicia es tema que, aún hoy, sigue siendo objeto de polémica.

Uno de los principales aspectos discutidos - si no el que másde la institución es el de cuál debe ser la relación entre el Ministerio Fiscal y el Ejecutivo o, más exactamente, cuál es la posición constitucional del Ministerio Fiscal. Hay quienes opinan que el Ministerio Fiscal debe ser - como lo es hoy - un órgano de relación entre el Gobierno y la Administración de Justicia. Por el contrario, los críticos a la actual configuración de la institución apuestan por una configuración del Ministerio Público "a la italiana», esto es, por un Ministerio Fiscal integrado plenamente en el Poder Judicial, ajeno por completo al Gobierno, y cuyos miembros disfruten de las mismas garantías e idéntico status que Jueces y Magistrados. Con todo, conviene advertir que esta última teoría no deja de ser un desideratum. Y es que, pese a que en los últimos años ha existido un cierto acercamiento entre la carrera judicial y fiscal, lo cierto es que aquella relación de dependencia entre el Ministerio Fiscal y el Ejecutivo constituye un imperativo constitucional o, por decirlo de otra manera, un rasgo básico de la institución constitucionalmente impuesto. En este sentido parece claro que cualquier propuesta de independencia del Ministerio Público del Ejecutivo o de integración plena de la institución en el Poder Judicial debe pasar necesariamente por una reforma constitucional.

Igualmente problemáticos han resultado determinados aspectos relativos a la estructura y funcionamiento del Ministerio Fiscal. En este contexto, los problemas obedecen a factores bien diversos: 
De un lado, y por lo que hace al diseño organizativo del Ministerio Fiscal, hay quienes predican la conveniencia de descentralizar la institución, creando lo que gráficamente se han denominado «ministerios fiscales autonómicos». La propuesta - aunque legítima - no se halla amparada por el artículo 124, pues, en la medida en que dicho precepto configura el principio de unidad como principio rector del funcionamiento del Ministerio Fiscal, veta la posibilidad de transferir los aspectos organizativos de la institución a las Comunidades Autónomas o de erigir las distintas Fiscalias en órganos autonómicos. El problema, por tanto, es similar al anteriormente apuntado, es decir, al relativo al grado de dependencia que debe mantener el Ministerio Fiscal respecto del Gobierno.

Por otro lado, y por lo que respecta a la función que el Ministerio Fiscal está llamado a desempeñar en el ámbito procesal, los problemas responden no a la contundencia del texto constitucional, sino más bien a su ambigüedad. Así, por ejemplo, es evidente que el artículo 124 ampara tanto el actual modelo de proceso penal, en que la instrucción corresponde al Juez, como un modelo - reivindicado por algunos - en que la instrucción quede en manos del Fiscal tal y como ha sucedido con la Justicia penal de menores (L.O. 5/1995, de 13 de enero, de responsabilidad penal del menor).

Apuntados los problemas que plantea el Ministerio Fiscal desde su diseño constitucional, lo cierto es que, durante estos veinticinco años, la actuación del Ministerio Fiscal como elemento esencial de la Administración de Justicia se ha visto potenciada desde su propio Estatuto orgánico (regulado por Ley 59/1981, de 30 de diciembre) y desde las últimas reformas procesales. Tal ha sido, paradigmáticamente, el caso de la Ley $1 / 2000$, de 7 de enero, de Enjuiciamiento Civil, y de la Ley 38/2002, de 24 de octubre, de reforma parcial de la Ley de Enjuiciamiento Criminal (más conocida como Ley de «juicios rápidos»). Así, en el ámbito del proceso civil, la actuación del Fiscal se justifica fundamentalmente por su condición de defensor constitucional de los intereses públicos que subyacen a determinados procesos como los matrimoniales o a aquéllos en que están en juego intereses de menores o incapaces; en el ámbito penal, la ya citada Ley 38/2002, y su complementaria, la Ley Orgánica 8/2002, abundan en la línea -iniciada por otras reformas procesales - de atribuir mayor protagonismo al Fiscal en el proceso penal, aunque no hasta el punto de confiarle la dirección de la fase de instrucción.

El incremento de las funciones que se han encomendado al Ministerio Público de un tiempo a esta parte ha exigido un progresivo 
aumento de su plantilla, que hoy ronda aproximadamente los 1.700 Fiscales, así como un replanteamiento de la organización y funcionamiento del Ministerio Fiscal mediante sucesivas reformas al Estatuto Orgánico del Ministerio Fiscal. Así, y entre las últimas, la operada por Ley $14 / 2003$, de 26 de mayo, en cuya virtud se establece la temporalidad en el desempeño de cargos jerárquicos del Ministerio Fiscal y se incorporan los criterios de mérito, especialización y formación, junto con el de la antigüedad, para la promoción en la carrera fiscal de forma similar a lo previsto en la Ley Orgánica del Poder Judicial para Jueces y Magistrados.

\section{La policía judicial}

La función auxiliar que la policía judicial realiza en el ámbito de la Administración de Justicia llevó al constituyente a incluir aquélla en elTítulo VI. La inclusión se realizó en los siguientes términos: "La policía judicial depende de los jueces, de los Tribunales y del Ministerio Fiscal en sus funciones de averiguación del delito y descubrimiento y aseguramiento del delincuente en los términos que la Ley establezca" (art. 126). Dada la generalidad con que se expresa, la definición constitucional de la policía judicial puede calificarse de fórmula abierta y de "mínimos».

Abierta, en tanto la Constitución no diseña un modelo claro de policía judicial; antes al contrario. Así las cosas, es evidente que, en la literalidad del artículo 126, tiene cabida tanto un modelo de policía judicial que dependa orgánicamente y funcionalmente del Poder Judicial y del Ministerio Fiscal, como un modelo de policía que dependa orgánicamente de la Administración y funcionalmente de los Tribunales $y$ del Ministerio Fiscal.

Y de "mínimos" porque, además de imperar la dependencia funcional de la policía de los Tribunales y del Ministerio Fiscal, establece como función propia de aquélla la averiguación del delito y descubrimiento del delincuente, lo que, obviamente, supone circunscribir su actuación al proceso penal.

El desarrollo legal de esa fórmula se ha concretado, de una parte, en la adopción de un modelo de policía judicial que, aunque orgánicamente dependiente del Ministerio del Interior, de las correspondientes Consejerías de las Comunidades Autónomas o de los Entes Locales, depende funcionalmente de losTribunales y del Ministerio Fiscal; $y$, de otra parte, en una ampliación de las funciones que, en su con- 
dición de personal auxiliar de la Administración de Justicia, se encomendaron constitucionalmente a la policía judicial. El desarrollo a que nos referimos se ha llevado a cabo fundamentalmente en virtud de la Ley Orgánica del Poder Judicial y de la Ley Orgánica 2/1986, de 13 de marzo, de Fuerzas y Cuerpos de Seguridad del Estado. La primera de las normas apuntadas - la Ley Orgánica del Poder Judicial- discierne dos conceptos de policía judicial: uno, con una connotación netamente funcional, $y$ en el que se incluyen todos los miembros de las Fuerzas y Cuerpos de Seguridad que pueden ser requeridos para prestar su colaboración con la Administración de Justicia; y otro, más restringido que el anterior y de connotación orgánica, en el que se comprenden las denominadas Unidades especializadas de la Policía Judicial. A estas últimas Unidades de Policía Judicial se refieren también los artículos 29 y ss. de la ya citada Ley Orgánica 2/1986, asi como el Real Decreto 769/1987, de 19 de junio.

Por otra parte, también se han ampliado las funciones de la policía judicial en el ámbito de la Administración de Justicia: la actuación encaminada a la averiguación de los delitos y al descubrimiento de los delincuentes es sólo una de las numerosas funciones que, en el ámbito de un proceso penal y fuera de él, se han atribuido legalmente a la policía judicial. Con todo, conviene reconocer que aquella función ha tenido un protagonismo destacado en las últimas reformas procesales, tanto es así que el éxito del reciente procedimiento para el enjuiciamiento rápido inmediato de determinados delitos y faltas depende en muy alto grado de la actuaciones pre-procesales que se confían a la policía, entre las que, además de las dirigidas a la averiguación del hecho punible y a la investigación del delincuente, se hallan otras muchas cuyo objetivo común es allanar el camino al Juez de Instrucción.

\section{PRINCIPIOS PROCESALES}

El Título VI del Poder Judicial comprende una serie de disposiciones que, más que referirse a los integrantes de ese Poder o a sus colaboradores, tienen que ver con el ejercicio de la actividad jurisdiccional o con la forma en que ésta se dispensa. De aquí, que pueda hablarse de principios procesales. No obstante, conviene precisar que esta expresión no se utiliza en sentido técnico-jurídico, ya que, desde esta perspectiva, principios procesales son sólo aquellos criterios que determinan los rasgos intrínsecos del proceso y sus características básicas, lo que no es el caso. 
El artículo 120 de la Constitución impera, en sus apartados 1 y 2 , que la actividad procesal sea predominantemente oral, sobre todo en materia criminal, y pública, con las excepciones que prevean las leyes de procedimiento. Durante mucho tiempo ambas previsiones - cuya existencia y formulación constitucional son discutibles - sólo tuvieron reflejo en la LOPJ (art. 229.1 y arts. 232 y ss.), sin que pudiera hablarse propiamente de desarrollo legislativo, sobre todo en lo que hace a la oralidad. Con los años, sin embargo, el legislador procesal ha potenciado ambas características, hasta el punto de poder afirmar que la oralidad y la publicidad constituyen, a día de hoy, las características generales de los procesos civiles y penales, y la escritura y el secreto de las actuaciones lo excepcional. Con todo, lo cierto es que, actualmente, no existe un proceso que sea completamente oral, pues determinadas actuaciones (como la demanda y la contestación a la demanda en el proceso civil, o los escritos de calificación en el proceso penal) siguen realizándose por escrito.

Exigencia constitucional que también alcanza a la actividad jurisdiccional es la que concierne al deber de motivar siempre $y$ en todo caso las sentencias, así como a la necesidad de que éstas se pronuncien en audiencia pública (art. 120.3). Ambas exigencias han tenido en la práctica una suerte dispar. Así, mientras la necesidad de pronunciar en audiencia pública las sentencias es imperativo obviado en la práctica forense, el deber de motivar las sentencias y otras resoluciones judiciales ha pasado a considerarse exigencia derivada no sólo del art. 120.3 CE, sino también del derecho a la tutela judicial efectiva (art. 24.1). Esta conexión entre el artículo 120.3 y el derecho a la tutela judicial efectiva ha llevado al Tribunal Constitucional a matizar el contenido y extensión del deber de motivación (SSTC 150/1988; 24/1990; 25/1990; 14/1991; y 49/1992, entre otras muchas) y al legislador a concretar el alcance de ese deber en el ámbito procesal (art. 218.2 LEC).

Otra de las previsiones constitucionales relativas a la actividad jurisdiccional que ha sido objeto de concreción legislativa es la referente al obligado cumplimiento de las sentencias y demás resoluciones judiciales, así como al deber de prestar la colaboración requerida por los Jueces y Tribunales en el curso del proceso y en la ejecución de lo resuelto (art. 118). Uno y otro aspecto se regulan, en efecto, en los arts. 17 y 469 de la LOPJ, asi como en el art. 591 LEC, precepto este último que autoriza incluso al tribunal a imponer multas coercitivas periódicas a las personas y entidades que no presten la colaboración requerida por el tribunal en el curso de un proceso de ejecución. 
El desarrollo legislativo también ha alcanzado a la gratuidad de la justicia en los términos previstos en el artículo 219 de la Constitución. Este desarrollo se ha concretado finalmente en la Ley $1 / 1996$, de 10 de enero, de Asistencia Jurídica Gratuita, y en el Real Decreto 996/2003, de 25 de julio, por el que se ha aprobado el Reglamento de Asistencia Jurídica Gratuita. Ambas normativas regulan unitariamente la gratuidad de la justicia en todos los órdenes jurisdiccionales.

\section{LA PARTICIPACIÓN DE LA JURISDICCIÓN ORDINARIA EN LA DEFENSA DE LA CONSTITUCIÓN}

Es de destacar la gran labor de defensa de la Constitución que el Poder Judicial ha llevado a cabo a lo largo de más de dos décadas de aplicación constitucional; una labor que, aun diseñada por la Norma Suprema, se ha ido perfilando y creciendo a través de sus intervenciones. Pensemos al respecto en el inicio de esta andadura cuando elTribunal Constitucional en sentencias como la STC 80/1982, de 20 de diciembre, recuerda al Tribunal Supremo «el indudable valor de la Constitución como norma", afirmando, además, la obligatoriedad de no aplicar normas contrarias a la misma, debiendo, en todo caso, respetar su contenido y velar por su cumplimiento à través de mecanismos como la inaplicación de la legislación preconstitucional o el planteamiento de la cuestión de inconstitucionalidad. $Y$ es que si bien el Tribunal Constitucional es el intérprete supremo de la Constitución, tal y como establece el artículo 1 de la LOTC, no se erige en único, toda vez que los Jueces y Magistrados participan también activamente en esa labor de interpretación y por tanto de protección de la misma.

Como decimos, la jurisdicción ordinaria participa en la defensa de la Constitución de forma generalizada a través de la interpretación del ordenamiento conforme a la Constitución y, puntualmente, a través de distintos mecanismos que se articulan frente a estos tipos de agresión. Curiosamente esta labor de defensa no viene especificamente recogida en el Título VI de la Constitución, sino que se deriva de principios generales como el del sometimiento de los poderes públicos a la Constitución (art. 9.1), o el de supremacía constitucional (art. 9.3), y de determinados preceptos constitucionales como los artículos $53.2,163$ o la disposición derogatoria tercera, que hacen partícipe al Poder Judicial de esa labor de defensa a través de mecanismos como la cuestión de inconstitucionalidad, la posibilidad de inaplicar normas o disposiciones normativas con rango de ley que sean preconstitucionales o la protección de derechos y libertades fundamentales a tra- 
vés de la vía ordinaria. En resumidas cuentas, aun cuando existe la función general de interpretación del ordenamiento conforme a la Constitución, ésta se hace patente a través de las citadas vías.

En cuanto al control de la constitucionalidad de las normas que configuran nuestro ordenamiento jurídico, los Jueces y Tribunales ordinarios son los encargados del control de las normas preconstitucionales - función que comparten con elTribunal Constitucional, pues pueden optar por su inaplicación o por plantear la cuestión de inconstitucionalidad en caso de duda (STC 4/1981) -; de los decretos legislativos, en los que el control recae, igualmente, sobre las dos jurisdicciones (art. 86.2 CE y 27. 2. b) LOTC); y, por último, de las normas infra-legales o de carácter reglamentario, en cuyo caso ese control conlleva únicamente a su inaplicación, según establece el artículo 6 LOPJ.

El planteamiento de la cuestión de inconstitucionalidad es el cauce más directo de participación de los Jueces y Tribunales en el control de la constitucionalidad de las normas, pero en este caso con rango de ley. Así, cuando duden sobre su constitucionalidad con ocasión del caso que están conociendo, deberán plantear la cuestión de inconstitucionalidad ante el Tribunal Constitucional, pues en este caso el monopolio de la declaración de inconstitucionalidad lo ejerce de forma única el Tribunal Constitucional. El Tribunal Constitucional ha calificado la cuestión de inconstitucionalidad de uprincipal mecanismo de conexión entre la jurisdicción ordinaria y la constitucional», afirmando, además, que se trata no sólo de un derecho de los Jueces y Tribunales sino también de un deber, pues la cuestión de inconstitucionalidad asegura «la depuración continua del ordenamiento desde el punto de vista de la constitucionalidad de las leyes... resultado de una colaboración necesaria entre los órganos del Poder Judicial y el Tribunal Constitucional» (STC 17/1981, FJ 1).

El propio Tribunal Constitucional ha ido flexibilizando los requisitos procesales de planteamiento de este procedimiento de control en aras a un mayor control de la constitucionalidad de las normas con rango de ley, relativizando, en contraposición, el carácter de control concreto de este mecanismo de control difuso. Se ha tratado así de potenciar la participación de la jurisdicción ordinaria en esta importante labor de control.

Pese a la interpretación flexible que viene realizando el Tribunal Constitucional en materia de control de constitucionalidad, a nadie se le escapa que el recurso más utilizado ante la jurisdicción constitucional ha sido el recurso de amparo, saturando - tal y como sucede 
en otros países - el funcionamiento del alto Tribunal cuando en realidad la protección de derechos y libertades es tarea de los Jueces y Tribunales ordinarios y cuando el recurso de amparo se configura constitucionalmente como subsidiario. No es de extrañar por lo dicho que, desde diversos sectores de la doctrina, se haya propuesto la modificación del recurso de amparo constitucional, al objeto de lograr dos objetivos: la descongestión del Tribunal Constitucional y que el peso fundamental de la labor de protección de los derechos y libertades recaiga de forma real y efectiva sobre la jurisdicción ordinaria. La tendencia actual parece ser la de la objetivación del recurso de amparo constitucional bien a través de medidas procesales (endurecimiento del procedimiento de admisión), bien a través de medidas de contenido sustancial como la necesaria relevancia constitucional de este recurso, dejando en manos de la jurisdicción ordinaria el control subjetivo y casuístico del mismo. De esta tendencia se hace eco el Pacto de Estado sobre la Reforma de la Justicia en el que se propone la reforma de la Ley Orgánica delTribunal Constitucional en este sentido.

Por otro lado, pero sin abandonar lo relativo a la protección de derechos y libertades fundamentales a través de la vía ordinaria, conviene traer a la mente que la doble confluencia entre la jurisdicción ordinaria y constitucional en esta materia ha provocado no pocas fricciones entre ambas. Esa doble confluencia tiene su razón de ser en el artículo 53.2 de la Constitución, que establece una doble protección jurisdiccional de los derechos y libertades: por un lado, la tutela por parte de los tribunales ordinarios, o lo que se ha dado en llamar el amparo ordinario; $y$, por otro, el amparo constitucional ante el Tribunal Constitucional. Como decíamos, el hecho de que Tribunal Constitucional y la jurisdicción ordinaria compartan esta función se ha traducido en fricciones entre ambas jurisidicciones e incluso en algún conflicto constitucional como el producido entre la Sala $1 .{ }^{a}$ del Tribunal Supremo y elTribunal Constitucional como consecuencia de la anulación de una sentencia (STS de 30 de abril de 1992) con motivo de un proceso civil sobre investigación de paternidad y en la que el Tribunal Constitucional indicó cómo debía ser valorada la prueba para que no produjera vulneración de la tutela judicial efectiva (STC 7/1994, de 17 de enero); o el que se ha vuelto a producir con motivo del conocimiento de los recursos de amparo resueltos por SSTC 115/2000, de 5 de mayo, y 186/2001, de 17 de septiembre (caso conocido como Isabel Preysler).

Para finalizar lo relativo a la protección ordinaria de los derechos y libertades fundamentales es necesario destacar el vaciamiento de 
contenido que ha sufrido la Ley $62 / 1978$, de protección jurisdiccional de los derechos y libertades fundamentales de la persona, como consecuencia, en un primer momento, de la aprobación de la Ley de Jurisdicción Contencioso Administrativa, $y$, más recientemente, de la aprobación de la nueva Ley de Enjuiciamiento Civil y la reforma parcial de la Ley de Enjuiciamiento Criminal de 24 de octubre de 2002.

En cuanto a los conflictos territoriales, ya sean autonómicos o en defensa de la autonomía local, ambas jurisdicciones - ordinaria y constitucional - tienen competencia. Sin embargo, en los autonómi$\cos$ y debido a la coincidencia de objeto (disposiciones, resoluciones y actos u omisiones), no está claro que la jurisdicción constitucional esté articulada en torno al principio de exclusividad o de alternatividad, es decir, no está claro que la jurisdicción constitucional sea exclusiva o alternativa, lo que ha provocado no escasos problemas a la doctrina constitucionalista y procesalista.

Por lo que hace a la defensa de la autonomía local, desde 1999 -y como resultado de la modificación de la Ley Orgánica delTribunal Constitucional y por la Ley Orgánica 7/1999, de 21 de abril- existe la posibilidad de impugnar directamente normas con rango de ley ante el Tribunal Constitucional, cuando, con anterioridad a esta regulación, su control recaía en la jurisdicción ordinaria bien directamente ante las vulneraciones producidas por actos sin valor de ley, bien indirectamente a través del planteamiento de la cuestión de inconstitucionalidad, si se trataba de vulneraciones producidas por normas o disposiciones normativas con rango de ley.

Por tanto, y como conclusión, terminar diciendo que la jurisdicción ordinaria ha participado y participa de forma activa y necesaria en la defensa de la Constitución. Pero, quizás, lo que convierte su tarea en una labor de especial importancia es la continua y constante interpretación y aplicación de la Norma Fundamental, ya que la vulneración puede provenir no sólo por acción sino también y, quizás más difícilmente detectable, por omisión.

El balance que, durante estos años de vigencia de la Constitución, puede hacerse del Poder Judicial no puede ser sino positivo. Sus integrantes han venido realizando su función desde los parámetros que impone la ley, juzgando y haciendo ejecutar lo juzgado. Con ello, Jueces y Magistrados se erigen no sólo en los principales aplicadores de las normas jurídicas sino también en fiscalizadores de su cumplimiento. De ahí, su papel esencial e imprescindible en un Estado calificado por la propia Constitución como Estado de Derecho. 